\title{
Acute Radiation Dermatitis Evaluation with Reflectance Confocal Microscopy: A Prospective Study
}

\author{
Juras Kišonas ${ }^{1,2, *}$, Jonas Venius ${ }^{3,4}$, Mindaugas Grybauskas ${ }^{1}$, Daiva Dabkevičienè ${ }^{5}$, Arvydas Burneckis ${ }^{1}$ \\ and Ričardas Rotomskis ${ }^{4}(\mathbb{D}$ \\ 1 Department of Radiation Oncology, National Cancer Institute, LT-08660 Vilnius, Lithuania; \\ mindaugas.grybauskas@nvi.lt (M.G.); arvydas.burneckis@nvi.lt (A.B.) \\ 2 Department of Neurobiology and Biophysics, Vilnius University, LT-01513 Vilnius, Lithuania \\ 3 Medical Physics Department, National Cancer Institute, LT-08660 Vilnius, Lithuania; jonas.venius@nvi.lt \\ 4 Biomedical Physics Laboratory, National Cancer Institute, LT-08660 Vilnius, Lithuania; \\ ricardas.rotomskis@nvi.lt \\ 5 Biobank, National Cancer Institute, LT-08660 Vilnius, Lithuania; daiva.dabkeviciene@nvi.lt \\ * Correspondence: juras.kisonas@nvi.lt; Tel.: +370-61237696
}

Citation: Kišonas, J.; Venius, J.; Grybauskas, M.; Dabkevičienė, D.; Burneckis, A.; Rotomskis, R. Acute Radiation Dermatitis Evaluation with Reflectance Confocal Microscopy: A Prospective Study. Diagnostics 2021, 11, 1670. https://doi.org/10.3390/ diagnostics 11091670

Academic Editor: Sang Hwan Nam

Received: 20 July 2021

Accepted: 7 September 2021

Published: 13 September 2021

Publisher's Note: MDPI stays neutral with regard to jurisdictional claims in published maps and institutional affiliations.

Copyright: (c) 2021 by the authors. Licensee MDPI, Basel, Switzerland. This article is an open access article distributed under the terms and conditions of the Creative Commons Attribution (CC BY) license (https:/ / creativecommons.org/licenses/by/ $4.0 /)$.

\begin{abstract}
Background: During radiotherapy (RT), most breast cancer patients experience ionizing radiation (IR)-induced skin injury-acute radiation dermatitis (ARD). The severity of ARD is determined by a physician according to CTCAE or RTOG scales, which are subjective. Reflectance confocal microscopy (RCM) is a noninvasive skin imaging technique offering cellular resolution. Digital dermoscopy (DD) performed in conjugation with RCM can provide more information regarding skin toxicity. The purpose of this study is to create an RCM and DD features-based ARD assessment scale, to assess the association with CTCAE scale and possible predictive value. Methods: One hundred and three breast cancer patients during RT were recruited; every week, clinical symptoms of ARD (CTCAE scale) were evaluated and RCM, together with digital dermoscopy (DD), was performed. Results: According to RCM; after 2 RT weeks, exocytosis and/or spongiosis were present in $94 \%$ of patients; after 3 weeks, mild contrast cells (MMCs) were detected in 45\%; disarrayed epidermis (DE) was present in $66 \%$ of patients after 4 weeks and in $93 \%$ after 5 weeks; abnormal dermal papillae (ADP) were present in $68 \%$ of patients after 5 weeks. The coefficients of RCM features $\left(\mathrm{RCM}_{\text {coef }}\right)$ alone and together with dermoscopically determined erythema (RCM-ERY ${ }_{\text {coef }}$ ) were significantly associated with ARD severity grade. $\mathrm{RCM}_{\text {coef }}$ is a significant predictive factor for the clinical manifestation of ARD. Conclusions: RCM features of irradiated skin appear earlier than clinical symptoms, have a characteristic course, and allow the severity of ARD to be predicted.
\end{abstract}

Keywords: acute radiation dermatitis; reflectance confocal microscopy; breast cancer

\section{Introduction}

Whole breast radiotherapy (WBRT) after breast-conserving surgery (BCS) is the standard treatment for patients with breast cancer [1]. During RT, most breast cancer patients experience radiation-induced skin injury — acute radiation dermatitis (ARD) — and up to $30 \%$ of them suffer from a moderate or severe form of this side effect [2].

One of the most important risk factors for the severity of ARD is the IR dose to the skin. Definite erythema appears when a dose of more than 12 grays (Gy) of IR is delivered to the skin (2-3 weeks of RT). Dry desquamation can be diagnosed after 20 Gy (3-4 weeks of RT), and moist desquamation after a 30 Gy dose (>4 weeks of RT) [3].

In everyday practice, the severity of ARD is determined by a physician according to Common Terminology Criteria for Adverse Events (CTCAE) or Radiation Therapy Oncology Group (RTOG) scales. These scales are used to assess symptoms such as skin erythema, dry and moist desquamation, edema, bleeding, necrosis, and ulceration. The same scales are used in clinical studies investigating the efficiency of topical agents for ARD 
prevention and treatment. The progress of clinical studies searching for effective prevention and treatment for ARD has been slow [2], and one of the reasons is low-sensitivity and investigator-dependent diagnostics of skin changes.

Hypofractionated WBRT is increasingly being used, which reduces the severity of ARD [4], making it even more difficult to diagnose with classical methods. Consequently, the demand for more sensitive ARD diagnostic methods is increasing [5]. Moreover, ARD manifestation is observed in almost all RT patients, especially where higher IR doses are used, such as with head and neck cancer [6].

The histological features of ARD are not well understood, because it is rarely biopsied, mostly due to wound healing problems during RT. IR decreases collagen gene expression [7] and collagen quality, reduces proliferative ability, and causes molecular and subcellular changes [8], which can lead to wound healing complications for up to $30 \%$ of breast cancer patients who are biopsied during RT [9].

Noninvasive skin imaging techniques (optical biopsy) can replace histological examination, expand the knowledge of the pathogenesis, and improve the clinical diagnostics of ARD. Reflectance confocal microscopy (RCM), optical coherence tomography (OCT), and multiphoton microscopy (MPM) are the most frequently used in clinical trials and everyday practice optical biopsy techniques [10,11].

OCT can achieve up to $2-3 \mathrm{~mm}$ tissue depth but is limited to a relatively low image resolution of $1-15 \mu \mathrm{m}$ [12]. MPM provides high lateral $(<0.5 \mu \mathrm{m})$ and axial $(1.0 \mu \mathrm{m})$ resolution [13]. However, it uses expensive short-pulsed lasers and is mostly used for research. On the other hand, RCM offers a similar resolution of $0.5-1.0 \mu \mathrm{m}$, uses a simple laser diode, and allows for the visualization of coetaneous structures with a resolution that is very close to that of light microscopy, thus performing a skin "optical biopsy" [14]. In addition to having a similar resolution, RCM also excels at convenient clinical application and is the most widely used skin imaging technique $[15,16]$.

RCM employs near-infrared light targeting the "optical window" of the skin and uses a low power (below $20 \mathrm{~mW}$ ) laser, which is below thermal threshold and causes no harm to the tissues, although the imaging depth is limited to the papillary dermis $(200-300 \mu \mathrm{m})$. During imaging, light penetrates the tissue and illuminates an estimated $0.5 \mu \mathrm{m}$ diameter point, and then the reflected light goes through a tiny pinhole, which does not allow the reflected light from the nearby tissue point to reach the detector. The contrast of RCM images depends on the reflectivity of the tissue. Structures with high refractive index (such as melanin and keratin) appear bright in RCM [17].

RCM is mostly used in the diagnosis of melanocytic lesions, such as nevi and melanoma [18,19], but is also useful for nonmelanocytic skin lesions [20-22], inflammatory diseases [23,24], and treatment monitoring [25,26]. RCM has been used for the evaluation of ARD skin changes, and it was determined that RCM can detect IR-induced skin changes, but the results were obtained from only six patients [27]. In one patient case study, it was also demonstrated that IR-induced skin changes in RCM images appear earlier than the occurrence of clinical symptoms [28].

A conventional RCM device is equipped with a dermoscope, which can provide more information regarding skin toxicity associated with RT [29]. The possibility of jointly employing digital dermoscopy (DD) with RCM for the better diagnosis of ARD is promising in terms of effective results of this combination in other fields [30,31].

Here, we present the results of a prospective, single center biomedical study including 103 breast cancer patients. The aim of this study is to create an RCM and DD features-based ARD assessment scale, to assess the association with CTCAE scale and possible predictive value. We found that the first signs of IR-induced skin lesions can be detected after the first week of RT; these violations have a typical course and can even predict the severity of the clinical symptoms of ARD. 


\section{Materials and Methods}

\subsection{Study and Patients}

This prospective, open-label single center biomedical study (protocol No. II-2016-4) was approved (permission No. 158200-17-908-418) by the local bioethics committee in April 2017. Inclusion criteria were those aged $>18$ years, prescribed RT after BCS for local breast cancer, and exhibited good performance status (ECOG 0-2). Exclusion criteria were those who exhibited poor performance status (ECOG $\geq 3$ ), undergone previous treatment with RT, or chemotherapy. A total of one hundred and ten patients with local breast cancer undergoing whole breast irradiation after BCS in the National Cancer Institute of Lithuania from April 2017 to February 2020 were recruited. A total of 103 patients with all RCM measurements were included in this paper from those who finished (108) the treatment.

\subsection{Radiotherapy and Clinical ARD Assessment}

Study patients were Caucasian women diagnosed with early-stage breast cancer and treated with BCS. According to the breast cancer treatment guidelines, whole breast RT was prescribed to all the patients. All patients were treated using the conventional 3D-RT technique. The prescribed dose to the breast planning target volume (PTV) was 50 Gy delivered in 2 Gy per fraction ( $\mathrm{fx}$ ), $5 \mathrm{fx}$ per week.

A clinical assessment of ARD symptoms, according to the Common Terminology Criteria for Adverse Events (CTCAE) grading scale (Table 1), was performed before RT and once a week (every $5 \mathrm{fx}$ ). A total of three radiation oncologists separately evaluated radiation-induced skin reactions. The evaluations were combined, and the final degree of ARD was determined when at least two evaluators agreed.

Table 1. Common Terminology Criteria for Adverse Events (CTCAE) grading scale for acute radiation dermatitis.

\begin{tabular}{|c|c|c|c|c|c|}
\hline \multirow{2}{*}{ Adverse Event } & \multicolumn{5}{|c|}{ Grade } \\
\hline & 1 & 2 & 3 & 4 & 5 \\
\hline $\begin{array}{l}\text { Radiation } \\
\text { Dermatitis }\end{array}$ & $\begin{array}{l}\text { Faint erythema or } \\
\text { dry desquamation }\end{array}$ & $\begin{array}{l}\text { Moderate to brisk } \\
\text { erythema; patchy } \\
\text { moist desquamation, } \\
\text { mostly confined to } \\
\text { skin folds and creases; } \\
\text { moderate edema }\end{array}$ & $\begin{array}{l}\text { Moist desquamation } \\
\text { in areas other than } \\
\text { skin folds and } \\
\text { creases; bleeding } \\
\text { induced by minor } \\
\text { trauma or abrasion }\end{array}$ & $\begin{array}{l}\text { Life-threatening } \\
\text { consequences; skin } \\
\text { necrosis or ulceration } \\
\text { of full thickness dermis; } \\
\text { spontaneous bleeding } \\
\text { from involved site; skin } \\
\text { graft indicated }\end{array}$ & Death \\
\hline
\end{tabular}

\subsection{Digital Dermoscopy}

Dermoscopic images were taken before every RCM imaging with a VivaCam ${ }^{\circledR}$ digital dermoscope (MAVIG GmbH, Munich, Germany) that uses a 2 MP CCD camera. These full-HD resolution images were used to assess the erythema (ERY) of the skin. A total of three radiation oncologists separately evaluated skin ERY according to a scale from 0 to 2, where 0 means "no erythema", 1 means "faint erythema", and 2 means "severe erythema". The evaluations were combined, and the final grade was determined when at least two evaluators agreed.

\subsection{Assessment of Skin Lesions with RCM}

RCM images were taken with the commercially available VivaScope ${ }^{\circledR} 1500$ (MAVIG $\mathrm{GmbH}$, Munich, Germany) medical device, which uses $830 \mathrm{~nm}$ wavelength, a $20 \mathrm{~mW}$ (max power) laser diode for tissue illumination, and a $30 \times$ magnification 0.9 NA water immersion objective for laser beam focusing onto the tissue and reflected light collection. The VivaScope ${ }^{\circledR} 1500$ provides a lateral resolution of $1.25 \mu \mathrm{m}$ and an axial resolution of $5.0 \mu \mathrm{m}$. The size of individual images is $500 \times 500 \mu \mathrm{m}$, with a frame rate of 9 images per second. The maximum mapped field is $8 \times 8 \mathrm{~mm}^{2}$, the image resolution is $1024 \times 1024$ pixels, and the resultant magnification is $520 \times$. 
In the beginning of the imaging session, firstly, mosaic confocal reflectance images of $4 \mathrm{~mm}$ by $4 \mathrm{~mm}$ in the spinose-granular skin layer were taken. After that, $500 \mu \mathrm{m}$ by $500 \mu \mathrm{m}$ images every $5 \mu \mathrm{m}$ up to $100 \mu \mathrm{m}$ of depth were taken at three selected points. All of the images were evaluated by two observers. A lesion was graded as 1 if it was present in less than $50 \%$ of images and 2 if in more than $50 \%$.

\subsection{Statistical Analysis}

Statistical analysis was used to describe characteristics of patients to compare different patient groups. For the descriptive statistics, scale variables were described by median and standard deviation and categorical variables by frequency of distribution. Ordinal logistic regression with sorted cases by subject and within-subject variables, and a Chisquare (X2) test, were used to determine the association between variables with similar radiotherapy fractions. Binary logistic regression was used to evaluate the association between variables with different radiotherapy fractions. The differences were considered statistically significant if a $p$-value was less than 0.05 . Statistical analysis was performed using IBM-SPSS Statistics 21 (SPSS, Inc., Chicago, IL, USA).

\section{Results}

After the exclusion of a patient with missing RCM imaging, a total of 103 subjects were included in the further analysis, except for a few cases when moist desquamation appeared at the end of RT and RCM was discontinued.

All of the patients were females from 28 to 76 years old, with an average age of 57.1 years \pm 8.97 (CI: 55.35-58.85). Study patient characteristics are shown in Table 2 .

Table 2. Study patient characteristics.

\begin{tabular}{ccc}
\hline \multicolumn{2}{c}{ Characteristic } & Result \\
\hline Patients (N) & & $103(100 \%)$ \\
\hline Gender & Female & $103(100 \%)$ \\
\hline \multirow{2}{*}{ Age (y) } & Mean, SD & $57.1 \pm 8.97$ \\
& Median & 56.6 \\
Stage & Min-max & $28-76$ \\
& 0 & $26(25.2 \%)$ \\
HT & I & $52(50.5 \%)$ \\
& II & $25(24.3 \%)$ \\
\hline \multirow{2}{*}{ Histology } & Yes & $70(68.0 \%)$ \\
& No & $33(32.0 \%)$ \\
\hline \multirow{2}{*}{ Radiotherapy } & DCIS & $24(23.3 \%)$ \\
& IDC & $63(61.2 \%)$ \\
& ILC & $11(10.7 \%)$ \\
& Other & $5(4.8 \%)$ \\
\hline
\end{tabular}

y-years, N-number, SD—standard deviation, min-minimum, max-maximum, HT-hormonotherapy, DCIS - ductal carcinoma in situ, IDC —invasive ductal carcinoma, ILC —invasive lobulal carcinoma, Gy-grays, Dmean-mean dose, CTV—clinical target volume, HI-homogeneity index, Dmax-maximum dose.

\subsection{Clinical ARD Assessment}

Clinical ARD assessment according to the CTCAE grading scale is presented in Table 3. 
Table 3. Clinical evaluation of ARD according to CTCAE grading scale.

\begin{tabular}{cccccccc}
\hline \multicolumn{2}{r}{ CTCAE Grade } & $\mathbf{0 ~ f x}$ & $\mathbf{5} \mathbf{f x}$ & $\mathbf{1 0} \mathbf{f x}$ & $\mathbf{1 5} \mathbf{f x}$ & $\mathbf{2 0} \mathbf{f x}$ & $\mathbf{2 5} \mathbf{f x}$ \\
\hline & 0 & $103(100 \%)$ & $90(87.4 \%)$ & $61(59.2 \%)$ & $21(20.4 \%)$ & $7(6.8 \%)$ & 0 \\
\multirow{2}{*}{ ARD } & I & 0 & $13(12.6 \%)$ & $41(39.8 \%)$ & $80(77.77 \%)$ & $68(66.0 \%)$ & $43(41.7 \%)$ \\
& II & 0 & 0 & $1(1.0 \%)$ & $2(1.9 \%)$ & $28(27.2 \%)$ & $58(56.3 \%)$ \\
& III & 0 & 0 & 0 & 0 & 0 & $2(1.9 \%)$ \\
\hline
\end{tabular}

CTCAE—Common Terminology Criteria for Adverse Events grading scale; fx—radiotherapy fractions, ARD—acute radiation dermatitis.

The patients in this study experienced the same clinical manifestation of ARD (Table 3) as other patients during the whole breast 3D-RT [32].

\subsection{Dermoscopic Skin Imaging}

Before RT, the control measurement of DD was performed on all patients. During treatment, dermoscopic images were taken after every $5 \mathrm{fx}$. Consecutive DD images revealed the progression of skin ERY during RT, which is depicted in Figure 1.

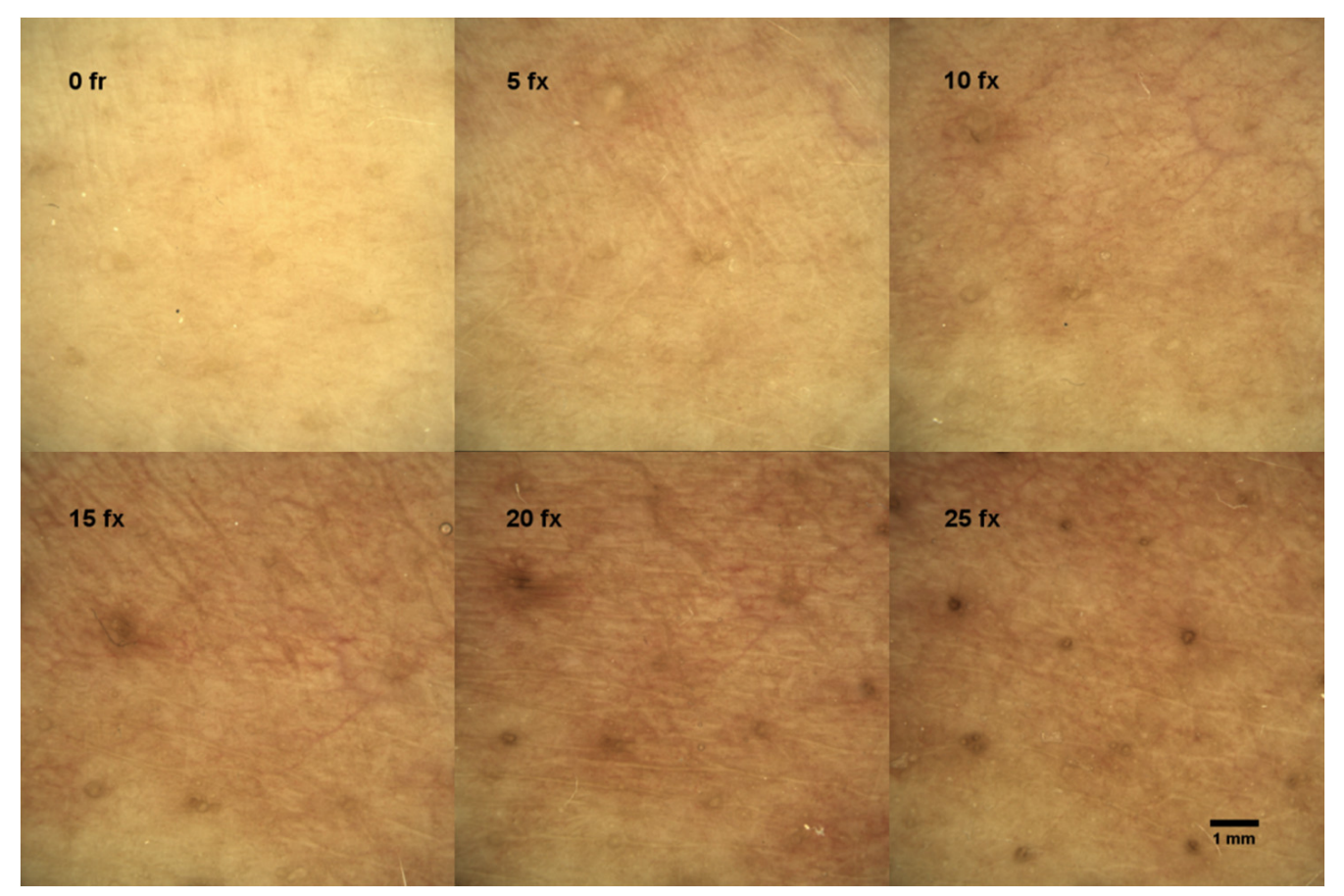

Figure 1. Dermascopic view of a single patient's skin changes indicating the progression of skin ERY during radiotherapy; $\mathrm{fx}$-radiotherapy fractions.

The ERY in the DD images was evaluated by three radiation oncologists according to a scale from 0 to 2, where 0 means "no ERY", 1 means "faint ERY", and 2 means "severe ERY". In the left upper corner of Figure 1, the dermoscopic view of the patient's skin before RT ( $0 \mathrm{fx})$ is demonstrated with no visual signs of ERY. All subsequent measurements were compared to the control. The example of the dermoscopic view of the faint ERY in a patient's skin after $5 \mathrm{fx}$ and $10 \mathrm{fx}$ is demonstrated in the middle and right upper corner of Figure 1, and severe ERY after $15 \mathrm{fx}, 20 \mathrm{fx}$, and $25 \mathrm{fx}$ in the bottom of Figure 1. The results of skin ERY evaluations from all patients' DD images are presented in Table 4. 
Table 4. The degree of skin erythema according to digital dermoscopy.

\begin{tabular}{cccccccc}
\hline DD & deg & $\mathbf{0} \mathbf{f x}$ & $\mathbf{5} \mathbf{f x}$ & $\mathbf{1 0} \mathbf{f x}$ & $\mathbf{1 5} \mathbf{f x}$ & $\mathbf{2 0} \mathbf{f x}$ & $\mathbf{2 5} \mathbf{f x}$ \\
\hline \multirow{4}{*}{ ERY } & 0 & $103(100 \%)$ & $71(68.9 \%)$ & $37(35.9 \%)$ & $16(15.5 \%)$ & $3(2.9 \%)$ & $2(1.9 \%)$ \\
& 1 & 0 & $31(30.1 \%)$ & $61(59.2 \%)$ & $78(75.7 \%)$ & $59(57.3 \%)$ & $28(27.2 \%)$ \\
& 2 & 0 & 0 & $3(2.9 \%)$ & $9(8.7 \%)$ & $39(37.9 \%)$ & $62(60.2 \%)$ \\
& $\mathrm{NP}$ & 0 & $1(1.0 \%)$ & $2(1.9 \%)$ & 0 & $2(1.9 \%)$ & $11(10.7 \%)$ \\
\hline
\end{tabular}

DD—digital dermoscopy; ERY—erythema; deg—degree of erythema in DD imaged, where 0 means "no erythema", 1 means "faint erythema", and 2 means "severe erythema"; fx-radiotherapy fractions; NPnot performed.

Ordinal logistic regression showed that a higher degree of skin ERY, determined with DD, was associated ( $p<0.0001)$ with a higher degree of ARD according to CTCAE scale.

In early fx (5 and 10), ERY using DD were diagnosed more frequently than according to the clinical evaluation (Table 3).

\subsection{Skin Lesion Assessment with RCM}

Before RT, the control measurement of RCM was performed on all patients. The representative view of the normal honeycomb pattern of epidermis before RT is shown in Figure 2a and the normal view of dermal papillae at the level of the dermo-epidermal junction (DEJ) in Figure 2b. All subsequent measurements were compared to the control.

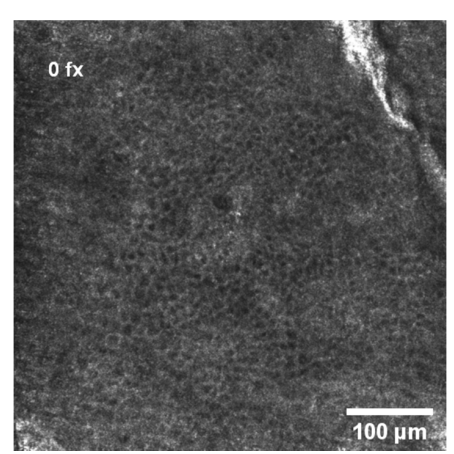

(a)

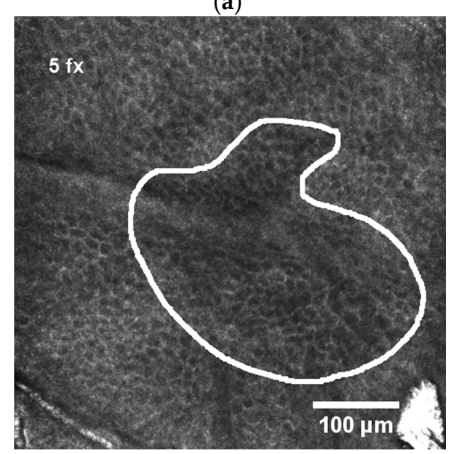

(c)

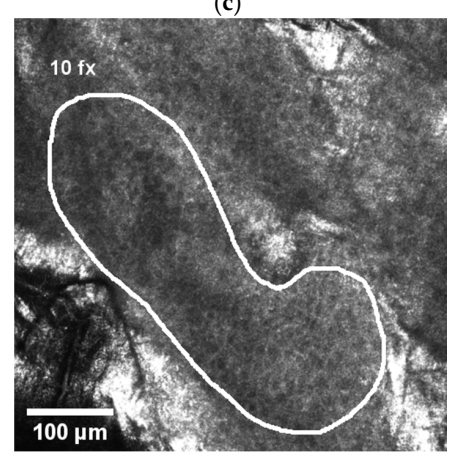

(e)

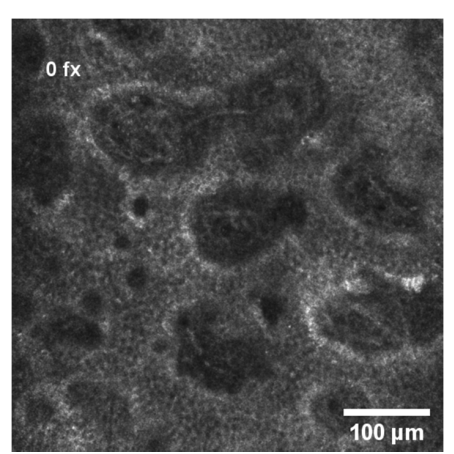

(b)

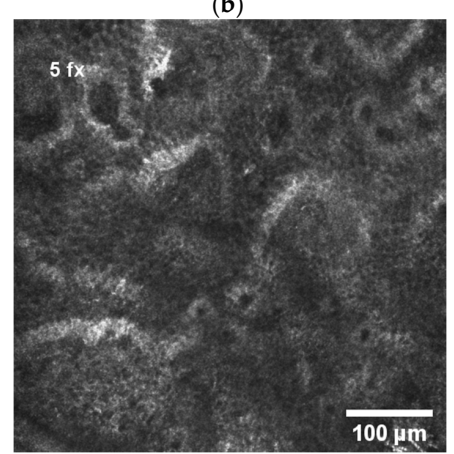

(d)

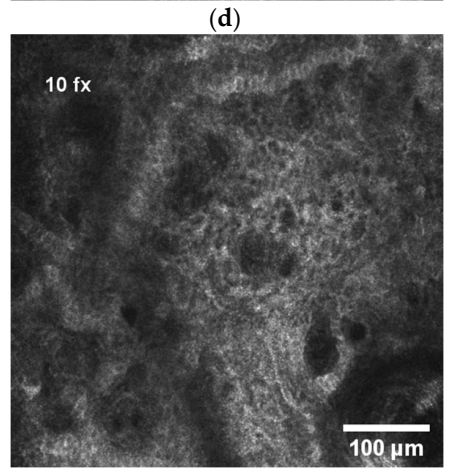

(f)

Figure 2. Cont. 


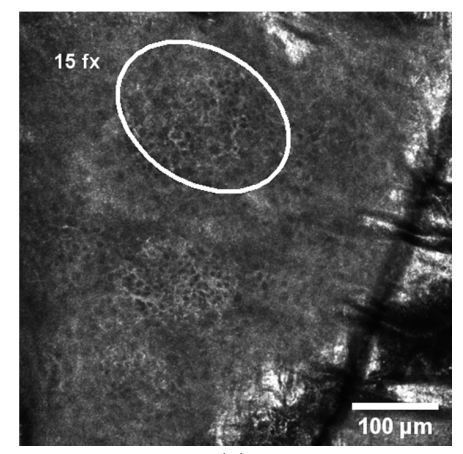

(g)

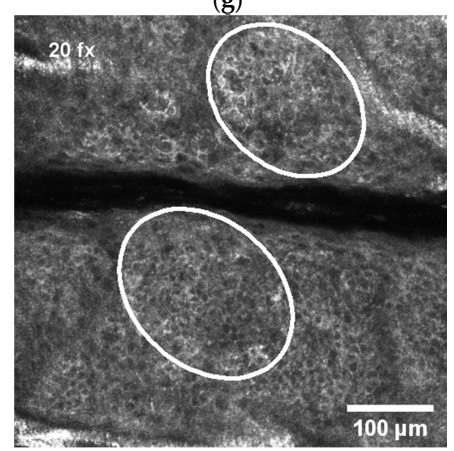

(i)

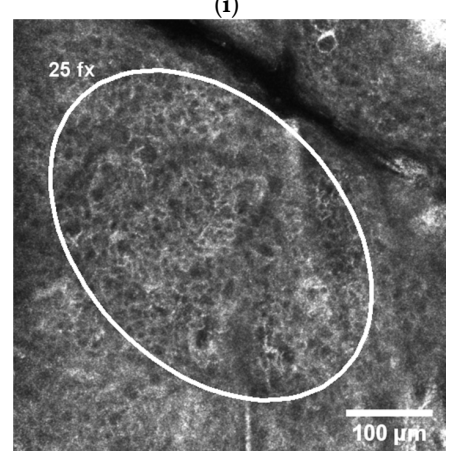

(k)

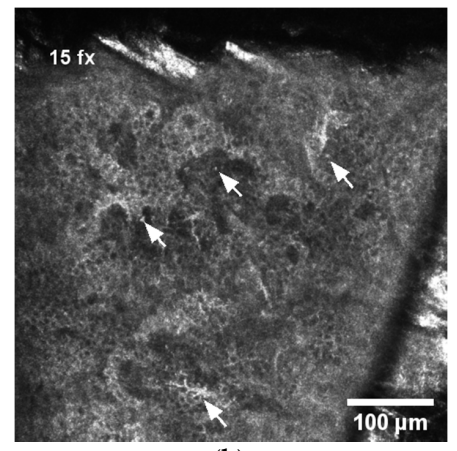

(h)

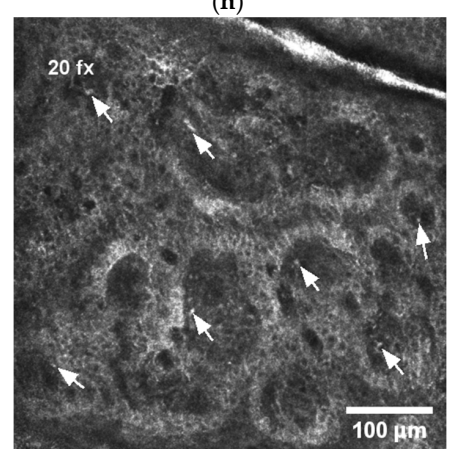

(j)

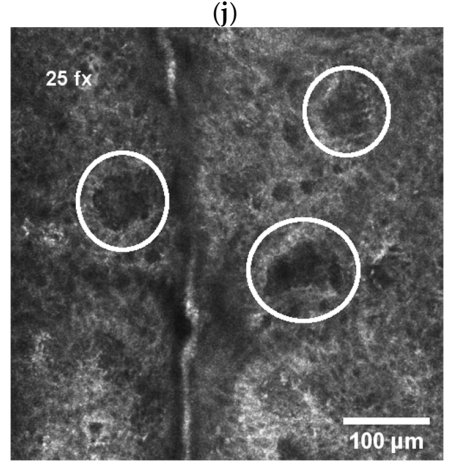

(1)

Figure 2. Dynamics of RCM features during radiotherapy: (a) normal honeycomb-like pattern of epidermis before radiotherapy; (b) normal view of dermal papillae in the dermo-epidermal junction (DEJ) before radiotherapy; (c) white line selection indicating exocytosis (aggregates of round-to-polygonal, mildly refractive cells) in epidermis after 5 radiotherapy fractions (fx); (d) normal view of dermal papillae in the DEJ after $5 \mathrm{fx}$; (e) white line selection indicating spongiosis (darker area relative to the surrounding epithelium of the stratum spinosum with intercellular spaces between keratinocytes larger than normal) and exocytosis in epidermis after $10 \mathrm{fx}$; (f) normal view of dermal papillae in the DEJ after $10 \mathrm{fx}$; (g) white line selection indicating the first signs of disarrayed epidermis (DE) after $15 \mathrm{fx}$; (h) white arrows indicating mild contrast cells (MMCs) in the DEJ after $15 \mathrm{fx}$; (i) white ovals indicating DE after $20 \mathrm{fx}$; (j) white arrows indicating MMCs in the DEJ after $20 \mathrm{fx}$; (k) white oval indicating large area of DE after $25 \mathrm{fx}$; (1) white circles indicating abnormal dermal papillae (ADP) after $25 \mathrm{fx}$.

The analysis of the first ten patients [33] revealed that spongiosis, exocytosis, and mild contrast cells (MCCs) are the early signs of radiation-induced skin injury, while disarrayed epidermis (DE) and abnormal dermal papillae (ADP) appear at the end of RT.

After $5 \mathrm{fx}$, the aggregates of round-to-polygonal cells corresponding to exocytosis (Figure 2c) were detected in $55.3 \%$ of all patients, but there were no alterations in the DEJ (Figure 2d). After $10 \mathrm{fx}$, an additional to exocytosis, the darker area relative to the surrounding epithelium of the stratum spinosum with intercellular spaces between larger than normal keratinocytes corresponding to spongiosis is demonstrated in Figure 2e, but still no alterations in the DEJ (Figure 2f). After $15 \mathrm{fx}$, the first signs of disarrayed epidermis (DE) were present in some patients' RCM images (Figure 2g). Simultaneously, at the level 
of DEJ a single, aggregates or diffuse round-to-polygonal, mildly refractive cells (MCCs) (Figure $2 \mathrm{~h}$ ) corresponding to inflammatory cells were detected. Exocytosis and spongiosis are the earliest and nonspecific symptoms characteristic for other inflammatory conditions as well [17], while MMCs are considered as the "hallmark" of IR-induced skin injury [3]. These three RCM symptoms do not cause structural damage of the skin. The harm to skin structure can be diagnosed when the normal honeycomb-like architecture at the level of the stratum spinosum is lost (disarrayed epidermis (DE)) or when bright papillary rims at the DEJ are absent (abnormal dermal papillae (ADP)). After $20 \mathrm{fx}$, broad DE (Figure 2i) and MMCs in the level of the DEJ (Figure 2j) were present. After $25 \mathrm{fx}$, extensive DE (Figure 2k) and ADP at the level of the DEJ (Figure 2l) could be detected.

The manifestations of RCM features of all study patients are presented in Table 5 .

Table 5. RCM features of all study patients.

\begin{tabular}{|c|c|c|c|c|c|c|c|}
\hline $\begin{array}{c}\text { RCM } \\
\text { Features }\end{array}$ & Int. & $0 \mathrm{fx}$ & $5 \mathrm{fx}$ & $10 \mathrm{fx}$ & $15 \mathrm{fx}$ & $20 \mathrm{fx}$ & $25 \mathrm{fx}$ \\
\hline \multirow{4}{*}{ Spongiosis } & 0 & $103(100 \%)$ & $75(72.8 \%)$ & $28(27.2 \%)$ & $9(8.7 \%)$ & $3(3.0 \%)$ & $1(1.1 \%)$ \\
\hline & 1 & 0 & $28(27.2 \%)$ & $73(70.9 \%)$ & $80(77.7 \%)$ & $63(62.4 \%)$ & $50(54.3 \%)$ \\
\hline & 2 & 0 & 0 & $2(1.9 \%)$ & $14(13.6)$ & $35(34.7 \%)$ & $41(44.6 \%)$ \\
\hline & NP & 0 & 0 & 0 & 0 & $2(1.9 \%)$ & $11(10.7 \%)$ \\
\hline \multirow{4}{*}{ Exocytosis } & 0 & $103(100 \%)$ & $46(44.7 \%)$ & $8(7.8 \%)$ & 0 & 0 & 0 \\
\hline & 1 & 0 & $57(55.3 \%)$ & $88(85.4 \%)$ & $59(57.3 \%)$ & $18(17.8 \%)$ & $7(7.6 \%)$ \\
\hline & 2 & 0 & 0 & $7(6.8)$ & $44(42.7 \%)$ & $83(82.2 \%)$ & $85(92.4 \%)$ \\
\hline & NP & 0 & 0 & 0 & 0 & $2(1.9 \%)$ & $11(10.7 \%)$ \\
\hline \multirow{4}{*}{ MMCs } & 0 & $103(100 \%)$ & 99 (96.1\%) & $86(83.8 \%)$ & $54(52.4)$ & $17(16.8 \%)$ & $2(2.2 \%)$ \\
\hline & 1 & 0 & $4(3.9 \%)$ & $17(16.5 \%)$ & $47(45.6)$ & $77(76.2 \%)$ & $65(70.7 \%)$ \\
\hline & 2 & 0 & 0 & 0 & $2(1.9 \%)$ & $7(6.9 \%)$ & $25(27.2)$ \\
\hline & NP & 0 & 0 & 0 & 0 & $2(1.9 \%)$ & $11(10.7 \%)$ \\
\hline \multirow{4}{*}{$\mathrm{DE}$} & 0 & $103(100 \%)$ & 103 (100\%) & $102(99.0 \%)$ & 78 (75.7\%) & $34(33.7 \%)$ & $4(4.3 \%)$ \\
\hline & 1 & 0 & 0 & $1(1.0 \%)$ & $24(23.3 \%)$ & $57(56.4 \%)$ & $43(46.7)$ \\
\hline & 2 & 0 & 0 & 0 & $1(1.0 \%)$ & $10(9.9 \%)$ & $45(48.9)$ \\
\hline & NP & 0 & 0 & 0 & 0 & $2(1.9 \%)$ & $11(10.7 \%)$ \\
\hline \multirow{4}{*}{$\mathrm{ADP}$} & 0 & $103(100 \%)$ & 103 (100\%) & 103 (100\%) & $102(99.0 \%)$ & $82(81.2 \%)$ & $29(31.5 \%)$ \\
\hline & 1 & 0 & 0 & 0 & $1(1.0 \%)$ & $19(18.8 \%)$ & $58(63.0 \%)$ \\
\hline & 2 & 0 & 0 & 0 & 0 & 0 & $5(5.4 \%)$ \\
\hline & NP & 0 & 0 & 0 & 0 & $2(1.9 \%)$ & $11(10.7 \%)$ \\
\hline
\end{tabular}

RCM-reflectance confocal microscopy; Int.-intensity of RCM features, where 1 means that the symptom is present in less than $50 \%$ of an image, and 2 in more than $50 \%$; fx-fractions of radiotherapy; MMC - mild contrast cell; DE—disarrayed epidermis; ADP—abnormal dermal papillae; NP_not performed.

By comparing these results with the degree of ARD (Table 3), we can clearly see that RCM features appear earlier.

\subsection{Clinical ARD Association with RCM and DD}

In order to compare the microscopic signs of radiation-induced skin injuries (spongiosis, exocytosis, MMCs, DE, and ADP) with clinical ARD evaluation (CTCAE scale), the coefficient of RCM features was calculated $\left(\mathrm{RCM}_{\text {coeff }}\right)$. Firstly, the sum of the RCM $\left(\mathrm{RCM}_{\text {sum }}\right)$ features was calculated according to Formula (1) as follows:

$$
\mathrm{RCM}_{\text {sum }}=\mathrm{S}, \mathrm{Emax}+\mathrm{MMC}+\mathrm{DE}+\mathrm{ADP}
$$

Here, spongiosis and exocytosis were counted as one symptom when only the maximum value of one of these symptoms was included in further calculations (S,Emax). The values of other symptoms (MMCs, DE, and ADP) were taken from Table 5.

$\mathrm{RCM}_{\text {sum }}$ was combined with $\mathrm{RCM}_{\text {coeff, }}$ according to symptom acuity. Nonspecific inflammatory changes such as low-grade spongiosis or exocytosis were assigned an $\mathrm{RCM}_{\text {coeff }}$ value of 0 . RCM symptoms that were reversible and corresponded to non-structural changes (such as higher grade spongiosis or exocytosis and MMCs) were assigned an $\mathrm{RCM}_{\text {coeff }}$ value of 1. High-grade symptoms causing damage to the skin structure were assigned an $\mathrm{RCM}_{\text {coeff }}$ value of $2 . \mathrm{RCM}_{\text {coeff }}$ values depending on $\mathrm{RCM}_{\text {sum }}$ are presented in Table 6. 
Table 6. $\mathrm{RCM}_{\text {coeff }}$ calculation from $\mathrm{RCM}_{\text {sum }}$.

\begin{tabular}{cc}
\hline $\mathbf{R C M}_{\text {sum }}$ & RCM $_{\text {coeff }}$ \\
\hline $0-1$ & 0 \\
$2-5$ & 1 \\
$6-8$ & 2 \\
\hline
\end{tabular}

$\overline{\mathrm{RCM}}_{\text {sum }}$-the sum of the reflectance confocal microscopy features, $\mathrm{RCM}_{\text {coeff }}$-the coefficient of reflectance confocal microscopy features.

$\mathrm{RCM}_{\text {coef }}$ values of all study patients are presented in Table 7.

Table 7. The values of $\mathrm{RCM}_{\text {coef }}$ of all study patients.

\begin{tabular}{cccccccc}
\hline $\mathbf{R C M}$ & $\mathbf{v a l}$ & $\mathbf{0} \mathbf{f} \mathbf{x}$ & $\mathbf{5} \mathbf{f x}$ & $\mathbf{1 0} \mathbf{f x}$ & $\mathbf{1 5} \mathbf{f x}$ & $\mathbf{2 0} \mathbf{f x}$ & $\mathbf{2 5} \mathbf{f x}$ \\
\hline \multirow{3}{*}{$\mathrm{RCM}_{\text {coef }}$} & 0 & $103(100 \%)$ & $97(96.0 \%)$ & $80(77.7 \%)$ & $41(39.8 \%)$ & 0 & 0 \\
& 1 & 0 & $4(4.0 \%)$ & $23(22.3 \%)$ & $60(58.3 \%)$ & $91(90.1 \%)$ & $46(50.0 \%)$ \\
& $\mathrm{NP}$ & 0 & 0 & 0 & $2(1.9 \%)$ & $10(9.9 \%)$ & $46(50.0 \%)$ \\
& 0 & $2(1.9 \%)$ & 0 & 0 & $2(1.9 \%)$ & $11(10.7 \%)$ \\
\hline
\end{tabular}

RCM-reflectance confocal microscopy, $\mathrm{RCM}_{\text {coeff }}$-the coefficient of reflectance confocal microscopy features, val—value, fx-radiotherapy fractions, NP—not performed.

Ordinal logistic regression revealed that a higher $\mathrm{RCM}_{\text {coeff }}$ is associated $(p<0.0001)$ with a higher degree of ARD, according to the CTCAE scale.

In order to compare the combination of RCM (spongiosis, exocytosis, MMCs, DE and $\mathrm{ADP})$ and DD (ERY) with clinical ARD manifestation (CTCAE scale), the coefficient of RCM and DD features was calculated (RCM-ERY coeff $)$. Firstly, the sum of the RCM and DD (RCM-ERY sum $)$ features was calculated according to Formula (2) as follows:

$$
\text { RCM-ERY } Y_{\text {sum }}=\mathrm{RCM}_{\text {sum }}+\mathrm{ERY}
$$

Here, $\mathrm{RCM}_{\text {sum }}$ is calculated as mentioned above (Formula (1)), and ERY is the degree of skin erythema according to DD from Table 5.

RCM-ERY ${ }_{\text {coeff }}$ can have values from 0 to 2 depending on RCM-ERY sum (Table 8).

Table 8. RCM-ERY ${ }_{\text {coeff }}$ calculation from RCM $_{\text {sum }}+$ ERY.

\begin{tabular}{cc}
\hline RCM-ERY & RCM-ERY $_{\text {coeff }}$ \\
\hline $0-1$ & 0 \\
$2-5$ & 1 \\
$6-10$ & 2
\end{tabular}

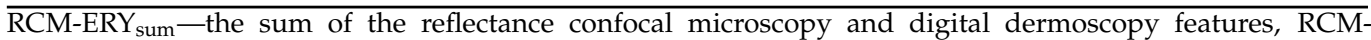
$E R Y_{\text {coeff }}$ - the coefficient of reflectance confocal microscopy and digital dermoscopy features.

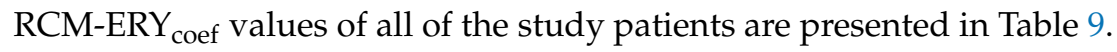

Table 9. The values of RCM-ERY ${ }_{\text {coef }}$ of all of the study patients.

\begin{tabular}{cccccccc}
\hline RCM & val & $\mathbf{0 ~ f x}$ & $\mathbf{5} \mathbf{f x}$ & $\mathbf{1 0} \mathbf{f x}$ & $\mathbf{1 5} \mathbf{f x}$ & $\mathbf{2 0} \mathbf{f x}$ & $\mathbf{2 5} \mathbf{f x}$ \\
\hline & 0 & $103(100 \%)$ & $79(78.2 \%)$ & $32(31.1 \%)$ & $13(12.6 \%)$ & 0 & 0 \\
RCM-ERY $_{\text {coef }}$ & 1 & 0 & $22(21.8 \%)$ & $70(68.0 \%)$ & $22(85.4 \%)$ & $66(65.3 \%)$ & $16(17.4 \%)$ \\
& 2 & 0 & 0 & $1(1.0 \%)$ & $2(1.9 \%)$ & $35(34.77 \%)$ & $76(82.6 \%)$ \\
& $\mathrm{NP}$ & 0 & $2(1.9 \%)$ & 0 & 0 & $2(1.9 \%)$ & $11(10.7 \%)$ \\
\hline
\end{tabular}

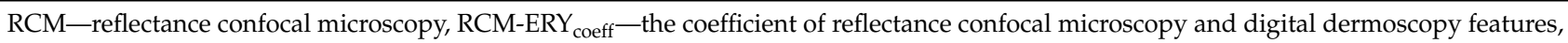
val—value, $\mathrm{fx}$-radiotherapy fractions, $\mathrm{NP}$ - not performed.

Ordinal logistic regression showed that a higher RCM-ERY coeff is associated $(p<0.0001)$ with higher degree of ARD, according to the CTCAE scale.

$\mathrm{A} \mathrm{X}^{2}$ test was used in order to compare clinical ARD assessment (CTCAE scale) with ERY, $\mathrm{RCM}_{\text {coeff, }}$ and $\mathrm{RCM}-\mathrm{DD}_{\text {coeff }}$ when measurements were performed after the same number of $\mathrm{fx}$ (Table 10). 
Table 10. ARD degree according to CTCAE scales association with DD and RCM findings calculated by $\mathrm{X}^{2}$.

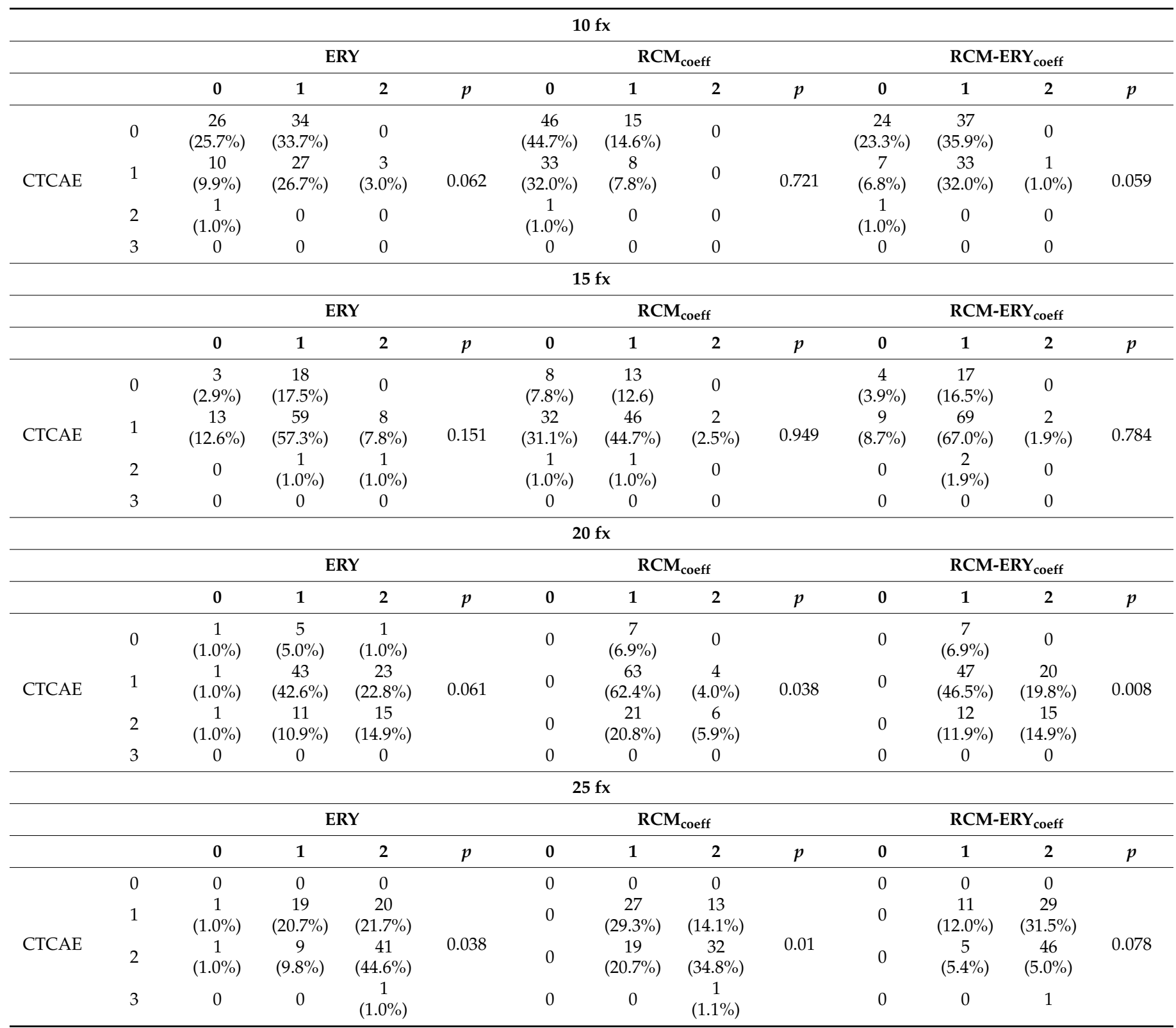

ARD—acute radiation dermatitis, CTCAE_Common Terminology Criteria for Adverse Events grading scale, DD—digital dermoscopy, ERY-erythema, RCM-reflectance confocal microscopy, $\mathrm{X}^{2}$ - Chi-square test, fx-radiotherapy fractions, $p$ - $p$-value of significance, $\mathrm{RCM}_{\text {coeff }}$-reflectance confocal microscopy coefficient, RCM-ERY ${ }_{\text {coeff }}$-reflectance confocal microscopy and digital dermoscopy coefficient.

After 20 RT fractions, the levels of ARD clinical grade (CTCAE scale) were significantly associated with the levels of both $\operatorname{RCM}_{\text {coeff }}(p=0.038)$ and RCM-ERY coeff $(p=0.008)$, as the frequency of the higher subgroup of CTCAE increased with the higher subgroup of $\mathrm{RCM}_{\text {coeff }}$ or RCM-ERY coeff, while after $25 \mathrm{fx}$, the ARD clinical grade (CTCAE scale) was significantly associated with the values of both $\operatorname{RCM}_{\text {coeff }}(p=0.01)$ and ERY $(p=0.038)$.

The next question was whether RCM and DD features, determined in the beginning of RT (from $10 \mathrm{fx}$ to $15 \mathrm{fx}$ ), could significantly distinguish CTCAE grade 1 from grade 2 determined at the end of RT (20 fx and $25 \mathrm{fx}$ ). For the same patient, an $\mathrm{RCM}_{\text {coeff }}$ value of 1 after $10 \mathrm{fx}$ and $15 \mathrm{fx}$ had a significantly higher odds ratio of grade 2 in the CTCAE scale after $20 \mathrm{fx}$ compared to grade 1 (Table 11). 
Table 11. Binary logistic regression of the diagnostic factors for CTCAE scale grades after $20 \mathrm{fx}$.

\begin{tabular}{ccccc}
\hline $\begin{array}{c}\text { Univariate } \\
\text { Analysis }\end{array}$ & \multicolumn{2}{c}{ Binary Logistic Regression } & \multicolumn{2}{c}{ AUC } \\
\hline Variable & OR (95\% C.I.) & $p$ Value & Area (95\% CI) & $p$ Value \\
\hline $\begin{array}{c}\text { RCMcoeff } 10 \mathrm{fx}: \\
1\end{array}$ & $\begin{array}{c}4.83(1.78-13.2) \\
-\end{array}$ & $\begin{array}{c}0.002 \\
\text { Ref. }\end{array}$ & $\begin{array}{c}0.64 \\
(0.52-0.76)\end{array}$ & 0.022 \\
\hline $\begin{array}{c}\text { RCMcoeff } 15 \mathrm{fx}: \\
1\end{array}$ & $14.5(4.0-52.1)$ & $\begin{array}{c}<0.001 \\
\text { Ref. }\end{array}$ & $\begin{array}{c}0.75 \\
(0.65-0.84)\end{array}$ & $<0.0001$ \\
\hline
\end{tabular}

OR-odds ratio; AUC-area under the receiver operating characteristics curve; C.I.-confidence interval; Ref.-reference group; RCM-ERY coeff - reflectance confocal microscopy and digital dermoscopy coefficient; $\mathrm{fx}-$ radiotherapy fractions.

Similarly, for the same patient, an $\mathrm{RCM}_{\text {coeff }}$ value of 1, determined after $15 \mathrm{fx}$, had a significantly higher odds ratio of grade 2 according to the CTCAE scale after $25 \mathrm{fx}$ compared to grade 1 (Table 12).

Table 12. Binary logistic regression of the diagnostic factors for CTCAE scale grades after $25 \mathrm{fx}$.

\begin{tabular}{|c|c|c|c|c|}
\hline \multirow{2}{*}{$\begin{array}{c}\text { Univariate Analysis } \\
\text { Variable }\end{array}$} & \multicolumn{2}{|c|}{ Binary Logistic Regression } & \multicolumn{2}{|c|}{ AUC } \\
\hline & OR (95\% C.I.) & $p$ Value & Area $(95 \% \mathrm{CI})$ & $p$ Value \\
\hline $\begin{array}{c}\text { RCMcoeff } 10 \mathrm{fx}: \\
1 \\
0\end{array}$ & $\begin{array}{c}5.0(0.6-40.4) \\
-\end{array}$ & $\begin{array}{l}0.131 \\
\text { Ref. }\end{array}$ & $\begin{array}{c}0.59 \\
(0.45-0.73)\end{array}$ & 0.24 \\
\hline $\begin{array}{c}\text { RCMcoeff } 15 \text { fx: } \\
1 \\
0\end{array}$ & $\begin{array}{c}8.8(2.3-33.8) \\
-\end{array}$ & $\begin{array}{l}0.001 \\
\text { Ref. }\end{array}$ & $\begin{array}{c}0.74 \\
(0.61-0.87)\end{array}$ & 0.002 \\
\hline
\end{tabular}

OR-odds ratio; AUC-area under the receiver operating characteristics curve; C.I.-confidence interval;

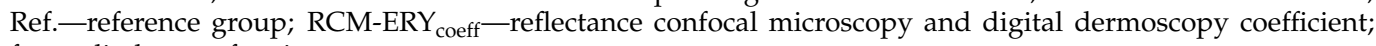
$\mathrm{fx}$-radiotherapy fractions.

In addition, the AUC estimates for $\mathrm{RCM}_{\text {coeff }}$ after $10 \mathrm{fx}$ and $15 \mathrm{fx}$ were also significant regarding CTCAE after $20 \mathrm{fx}$ and $25 \mathrm{fx}$ (Tables 9 and 10). Therefore, the results of this analysis showed that $\mathrm{RCM}_{\text {coeff }}$, determined at the beginning of RT, significantly distinguished between grades 1 and 2 of the CTCAE scale at the end of RT and could be considered as a promising predictive factor.

\section{Discussion}

ARD is a relevant clinical problem, but until now the efficacy of topical treatment has not been proven in large, randomized studies [2]. There is a lack of new methods that could improve the diagnostics of ARD and accelerate the development of new topical agents for the prevention and treatment of this side effect.

RCM is widely used for melanoma non-melanoma skin cancer diagnostics [34-37] and treatment management [38,39]. RCM as an optical biopsy method is also used for inflammatory skin diseases diagnostics and treatment monitoring [23,24,40].

The aim of this study was to create an RCM and DD features-based ARD assessment scale, to assess the association with CTCAE scale and possible predictive value. For this purpose, we recruited 103 breast cancer patients during RT and every week we evaluated the clinical symptoms of ARD (CTCAE scale) and performed RCM. Before every RCM, the full-HD image of the same skin region was taken with DD. Given that RCM can be difficult to apply in everyday practice, we also analyzed DD images (Figure 1) and compared them with clinical ARD manifestation (CTCAE scale).

To our knowledge, this is the first prospective clinical study with more than 100 patients analyzing radiation-induced skin injuries with RCM and DD. 
The first and, so far, the only study analyzing dynamic skin changes during RT using RCM was performed by Vano-Galvan and colleagues [27]. In our study, we investigated 103 patients and performed RCM once a week, while the Vano-Galvan study was conducted with 6 patients and RCM imaging every three weeks.

In our investigation, we performed more than 600 imaging sessions with RCM and DD. We found that by using RCM, the first symptoms of radiation-induced skin injury could be detected very early. After $5 \mathrm{fx}$, exocytosis or spongiosis was detected for $65 \%$ of all patients, and after $10 \mathrm{fx}, 94 \%$ of patients experienced IR-induced skin injury (Table 5). During clinical evaluation, however, an ARD degree of 1 was diagnosed for $13 \%$ of patients after $5 \mathrm{fx}$, and after $10 \mathrm{fx}$ only $40 \%$ of all patients were diagnosed with an ARD degree of 1 or 2 (Table 3 ).

According to RCM (Table 5 and Figure 2), radiation-induced skin changes have a typical course determined with RCM. After 2 weeks of RT (10 fx), exocytosis and/or spongiosis was detected for $94 \%$ of patients; after 3 weeks ( $15 \mathrm{fx}$ ), inflammatory cells (MMCs) were detected in $45 \%$ of patients, and this number increased until the end of RT; after 4 weeks (20 fx), DE was detected in $66 \%$ of patients and increased to $93 \%$ at the end of RT; after 5 weeks ( $25 \mathrm{fx}$ ), ADP was detected in $68 \%$ of patients.

Radiation-associated epidermal atypia was the main finding in RCM for basal cell carcinoma patients when the coetaneous response to RT was imaged in vivo [41]. The authors of this study suggested that epidermal atypia is likely a sign of ARD, which corresponds well with the findings of our study showing that at the end of RT, the majority of patients had pronounced DE.

For the more detailed comparison of RCM and DD symptoms with the clinical assessment of ARD, we created coefficients based on RCM and DD imaging results.

Ordinal logistic regression showed that the higher degree of ARD, according to the CTCAE scale, is associated with higher values of RCM coeff $_{\text {, ERY, and RCM-ERY }}$ coeff (Table 10). Comparing measurements after the same number of $\mathrm{fx}$, the strongest association between RCM or DD features and the CTCAE scale was found at the end of RT. After 4 RT weeks, $R_{C M}$ coeff and RCM-ERY coeff were significantly associated with the CTCAE scale grade, while after 5 weeks, similar results showed RCM $_{\text {coeff }}$ and ERY (Table 10).

The final step was to analyze RCM and DD features as possible predictive factors for the severity of ARD determined by the CTCAE scale. According to binary logistic regression, $\mathrm{RCM}_{\text {coeff }}$ determined in the beginning of RT (from $10 \mathrm{fx}$ to $15 \mathrm{fx}$ ) showed significant predictive value to distinguish the CTCAE grade 1 from grade 2 determined in the end ( $20 \mathrm{fx}$ and $25 \mathrm{fx}$ ) of RT (Tables 11 and 12).

These results are promising for integrating RCM into clinical studies or in everyday practice for the early detection of IR-induced skin changes and severity prediction. However, performing RCM requires time, effort, and a qualified specialist, which could be major limitations for applying it in clinical practice. On the other hand, DD is much easier to perform and interpret. Therefore, DD images could be analyzed by a physician and RCM by employing telediagnostics [42].

One of the possible limitations of this study is that all of the patients were Caucasian women. Some studies show that people with white skin have more severe clinical reactions to irritants compared to those with black skin [43]. A similar study with black skin patients should be conducted.

As mentioned above, there is a lack of clinical studies focusing on RCM application for skin changes during RT, but there are similar investigations with laboratory animals. For example, MPM used for early-stage radiation skin injury in a mouse model showed that after IR exposure, epidermal cells and intercellular spaces became large and irregular [44]. These symptoms correspond well with exocytosis and spongiosis in our study.

It was demonstrated that OCT angiography could non-invasively detect IR-induced changes in mouse skin, such as skin thickening, the dilation of large blood vessels, and irregularity in vessel boundaries [45]. 
Based on the results of this study, we propose RCM and DD as a sensitive tool for evaluation of IR-induced skin changes. The next step should be to analyze the benefits of RCM and DD in randomized clinical trials investigating the efficiency of topical agents for ARD prevention or treatment.

\section{Conclusions}

RCM reveals radiation-induced skin changes at the cellular level with no harm for the patient and could improve the assessment of skin condition during RT. RCM features of irradiated skin appear earlier than clinical symptoms, have a characteristic course, and allow for a prediction of the severity of ARD.

Author Contributions: Conceptualization, J.K. and J.V.; methodology, J.K. and J.V.; software, J.K.; validation, J.K., A.B. and M.G.; formal analysis, J.K., J.V., A.B., M.G. and D.D.; investigation, J.K., J.V., A.B. and M.G.; resources, A.B. and R.R.; data curation, J.K.; writing-original draft preparation, J.K.; writing-review and editing, J.K., J.V., A.B., M.G., D.D. and R.R.; visualization, J.K.; supervision, R.R.; project administration, J.K.; funding acquisition, A.B. and R.R. All authors have read and agreed to the published version of the manuscript.

Funding: This research received no external funding.

Institutional Review Board Statement: The study was conducted according to the guidelines of the Declaration of Helsinki and approved by the Vilnius Regional Ethics Committee for Biomedical Research (permission No.: 158200-17-908-418) of Vilnius University (protocol No. II-2016-4).

Informed Consent Statement: Informed consent was obtained from all subjects involved in the study.

Data Availability Statement: All data will be made available upon reasonable request to the corresponding author.

Acknowledgments: The authors would like to thank all the doctors in the Department of Radiation Oncology (National Cancer Institute, Vilnius, Lithuania) for their help with the ARD assessment.

Conflicts of Interest: The authors declare no conflict of interest.

\section{References}

1. Castaneda, S.A.; Strasser, J. Updates in the Treatment of Breast Cancer with Radiotherapy. Surg. Oncol. Clin. N. Am. 2017, 26, 371-382. [CrossRef]

2. Yee, C.; Wang, K.; Asthana, R.; Drost, L.; Lam, H.; Lee, J.; Vesprini, D.; Leung, E.; DeAngelis, C.; Chow, E. Radiation-induced Skin Toxicity in Breast Cancer Patients: A Systematic Review of Randomized Trials. Clin. Breast Cancer 2018, 18, e825-e840. [CrossRef]

3. Ryan, J.L. Ionizing Radiation: The Good, the Bad, and the Ugly. J. Investig. Dermatol. 2012, 132 Pt 2, 985-993. [CrossRef]

4. Valle, L.F.; Agarwal, S.; Bickel, K.; Herchek, H.A.; Nalepinski, D.C.; Kapadia, N. Hypofractionated whole breast radiotherapy in breast conservation for early-stage breast cancer: A systematic review and meta-analysis of randomized trials. Breast Cancer Res. Treat. 2017, 162, 409-417. [CrossRef] [PubMed]

5. Kole, A.J.; Kole, L.; Moran, M.S. Acute radiation dermatitis in breast cancer patients: Challenges and solutions. Breast Cancer Targets Ther. 2017, 9, 313-323. [CrossRef]

6. Häfner, M.; Fetzner, L.; Hassel, J.; Debus, J.; Potthoff, K. Prophylaxis of Acute Radiation Dermatitis with an Innovative FDAApproved Two-Step Skin Care System in a Patient with Head and Neck Cancer Undergoing a Platin-Based Radiochemotherapy: A Case Report and Review of the Literature. Dermatology 2013, 227, 171-174. [CrossRef] [PubMed]

7. Bernstein, E.F.; Salomon, G.D.; Harisiadis, L.; Talbot, T.; Harrington, F.; Russo, A.; Uitto, J. Collagen gene expression and wound strength in normal and radiation-impaired wounds. A model of radiation-impaired wound healing. J. Dermatol. Surg. Oncol. 1993, 19, 564-570. [CrossRef] [PubMed]

8. Dormand, E.-L.; Banwell, P.E.; Goodacre, T.E. Radiotherapy and wound healing. Int. Wound J. 2005, 2, 112-127. [CrossRef]

9. Pezner, R.D.; Lorant, J.A.; Terz, J.; Ben-Ezra, J.; Odom-Maryon, T.; Luk, K.H. Wound-Healing Complications Following Biopsy of the Irradiated Breast. Arch. Surg. 1992, 127, 321-324. [CrossRef]

10. Oh, B.H.; Kim, K.H.; Chung, K.Y. Skin Imaging Using Ultrasound Imaging, Optical Coherence Tomography, Confocal Microscopy, and Two-Photon Microscopy in Cutaneous Oncology. Front. Med. 2019, 6, 274. [CrossRef]

11. Csuka, E.A.; Ward, S.C.; Ekelem, C.; Bs, D.A.C.; Ardigò, M.; Mesinkovska, N.A. Reflectance Confocal Microscopy, Optical Coherence Tomography, and Multiphoton Microscopy in Inflammatory Skin Disease Diagnosis. Lasers Surg. Med. 2021, 53, 776-797. [CrossRef]

12. Fujimoto, J.G. Optical coherence tomography for ultrahigh resolution in vivo imaging. Nat. Biotechnol. 2003, $21,1361-1367$. [CrossRef] 
13. Dunn, K.W.; Young, P.A. Principles of Multiphoton Microscopy. Nephron 2006, 103, e33-e40. [CrossRef]

14. Diaconeasa, A.; Boda, D.; Neagu, M.; Constantin, C.; Constantin, C.; Vlădău, L.; Guțu, D. The role of confocal microscopy in the dermato-oncology practice. J. Med. Life 2011, 4, 63-74. [PubMed]

15. Ilie, M.A.; Caruntu, C.; Lixandru, D.; Tampa, M.; Georgescu, S.; Constantin, M.; Constantin, C.; Neagu, M.; Zurac, S.A.; Boda, D. In vivo confocal laser scanning microscopy imaging of skin inflammation: Clinical applications and research directions. Exp. Ther. Med. 2019, 17, 1004-1011. [CrossRef]

16. Ilie, M.A.; Caruntu, C.; Lupu, M.; Lixandru, D.; Tampa, M.; Georgescu, S.-R.; Bastian, A.; Constantin, C.; Neagu, M.; Zurac, S.A.; et al. Current and future applications of confocal laser scanning microscopy imaging in skin oncology. Oncol. Lett. 2019, 17, 4102-4111. [CrossRef]

17. Hofmann-Wellenhof, R. Reflectance Confocal Microscopy for Skin Diseases, 1st ed.; Hofmann-Wellenhof, R., Pellacani, G., Malvehy, J., Soyer, H.P., Eds.; Springer: Berlin, Germany, 2012; pp. 7-8.

18. Serban, E.-D.; Farnetani, F.; Pellacani, G.; Constantin, M.M. Role of In Vivo Reflectance Confocal Microscopy in the Analysis of Melanocytic Lesions. Acta Dermatovenerol. Croat. 2018, 26, 64-67.

19. Agozzino, M.; Moscarella, E.; Babino, G.; Caccavale, S.; Piccolo, V.; Argenziano, G. The use of in vivo reflectance confocal microscopy for the diagnosis of melanoma. Expert Rev. Anticancer Ther. 2019, 19, 413-421. [CrossRef] [PubMed]

20. Lupu, M.; Popa, I.M.; Voiculescu, V.M.; Caruntu, C. A Systematic Review and Meta-Analysis of the Accuracy of in Vivo Reflectance Confocal Microscopy for the Diagnosis of Primary Basal Cell Carcinoma. J. Clin. Med. 2019, 8, 1462. [CrossRef]

21. Nguyen, K.P.; Peppelman, M.; Hoogedoorn, L.; Van Erp, P.E.; Gerritsen, M.-J.P. The current role of in vivo reflectance confocal microscopy within the continuum of actinic keratosis and squamous cell carcinoma: A systematic review. Eur. J. Dermatol. 2016, 26, 549-565. [CrossRef]

22. Gouveia, B.M.; Wells, J.; Kim, J.; Consuegra, G.; Longo, C.; Fernandez-Penas, P. Systematic review and proposal of an in vivo reflectance confocal microscopy assessment tool for cutaneous lymphoma. J. Cutan. Pathol. 2020, 47, 295-304. [CrossRef]

23. Agozzino, M.; Gonzalez, S.; Ardigo, M. Reflectance Confocal Microscopy for Inflammatory Skin Diseases. Actas Dermo-Sifiliogr. 2016, 107, 631-639. [CrossRef]

24. Ardigò, M.; Prow, T.; Agozzino, M.; Soyer, P.; Berardesca, E. Reflectance confocal microscopy for inflammatory skin diseases. G. Ital. Dermatol. Venereol. 2015, 150, 565-573.

25. Nadiminti, H.; Scope, A.; Marghoob, A.A.; Busam, K.; Nehal, K.S. Use of Reflectance Confocal Microscopy to Monitor Response of Lentigo Maligna to Nonsurgical Treatment. Dermatol. Surg. 2010, 36, 177-184. [CrossRef]

26. Ulrich, M.; Krueger-Corcoran, D.; Roewert-Huber, J.; Sterry, W.; Stockfleth, E.; Astner, S. Reflectance Confocal Microscopy for Noninvasive Monitoring of Therapy and Detection of Subclinical Actinic Keratoses. Dermatology 2010, 220, 15-24. [CrossRef]

27. Vano-Galvan, S.; Fernandez-Lizarbe, E.; Truchuelo, M.; Diaz-Ley, B.; Grillo, E.; Sanchez, V.; Ríos-Buceta, L.; Paoli, J.; Sancho, S.; Montero, A.; et al. Dynamic skin changes of acute radiation dermatitis revealed by in vivo reflectance confocal microscopy. J. Eur. Acad. Dermatol. Venereol. 2013, 27, 1143-1150. [CrossRef]

28. Kišonas, J.; Venius, J.; Sevriukova, O.; Grybauskas, M.; Guogytè, K.; Burneckis, A.; Rotomskis, R. Application of reflectance confocal microscopy for early diagnosis of radiation-induced acute dermatitis in radiosensitive patient: Case study. Radiat. Prot. Dosim. 2018, 182, 93-97. [CrossRef]

29. Nazik, H.; Kurtul, N. Dermoscopy: As a new method for evaluation of radiation dermatitis in patients with breast cancer. Egypt. J. Dermatol. Venerol. 2019, 39, 25-30. [CrossRef]

30. De Carvalho, N.; Farnetani, F.; Ciardo, S.; Ruini, C.; Witkowski, A.; Longo, C.; Argenziano, G.; Pellacani, G. Reflectance confocal microscopy correlates of dermoscopic patterns of facial lesions help to discriminate lentigo maligna from pigmented nonmelanocytic macules. Br. J. Dermatol. 2015, 173, 128-133. [CrossRef]

31. Navarrete-Dechent, C.; Cordova, M.; Liopyris, K.; Rishpon, A.; Aleissa, S.; Rossi, A.; Lee, E.; Chen, C.; Busam, K.; Marghoob, A.; et al. Reflectance confocal microscopy and dermoscopy aid in evaluating repigmentation within or adjacent to lentigo maligna melanoma surgical scars. J. Eur. Acad. Dermatol. Venereol. 2020, 34, 74-81. [CrossRef]

32. McDonald, M.W.; Godette, K.D.; Butker, E.K.; Davis, L.W.; Johnstone, P.A. Long-Term Outcomes of IMRT for Breast Cancer: A Single-Institution Cohort Analysis. Int. J. Radiat. Oncol. 2008, 72, 1031-1040. [CrossRef] [PubMed]

33. Kišonas, J.V.J.; Sevriukova, O.; Grybauskas, M.; Burneckis, A.; Rotomski, R. Acute Radiodermatitis Clinical Manifestation in Comparison with Reflectance Confocal Microscopy. In Medical Physics in The Baltic States 2019; Adliene, D., Ed.; Kaunas University of Technology: Kaunas, Lithuania, 2019; pp. 66-70.

34. Xiong, Y.-Q.; Ma, S.; Li, X.; Zhong, X.; Duan, C.; Chen, Q. A meta-analysis of reflectance confocal microscopy for the diagnosis of malignant skin tumours. J. Eur. Acad. Dermatol. Venereol. 2016, 30, 1295-1302. [CrossRef]

35. Pezzini, C.; Kaleci, S.; Chester, J.; Farnetani, F.; Longo, C.; Pellacani, G. Reflectance confocal microscopy diagnostic accuracy for malignant melanoma in different clinical settings: Systematic review and meta-analysis. J. Eur. Acad. Dermatol. Venereol. 2020, 34, 2268-2279. [CrossRef]

36. Pellacani, G.; De Pace, B.; Reggiani, C.; Cesinaro, A.M.; Argenziano, G.; Zalaudek, I.; Soyer, H.P.; Longo, C. Distinct melanoma types based on reflectance confocal microscopy. Exp. Dermatol. 2014, 23, 414-418. [CrossRef]

37. Edwards, S.J.; Mavranezouli, I.; Osei-Assibey, G.; Marceniuk, G.; Wakefield, V.; Karner, C. VivaScope ${ }^{\circledR} 1500$ and 3000 systems for detecting and monitoring skin lesions: A systematic review and economic evaluation. Health Technol. Assess. 2016, $20,1-259$. [CrossRef] 
38. Navarrete-Dechent, C.; Cordova, M.; Aleissa, S.; Shoushtari, A.; Hollmann, T.J.; Leitao, M.M.; Rossi, A.M. Monitoring vulvar melanoma response to combined immunotherapy and radiotherapy with in vivo reflectance confocal microscopy. J. Dtsch. Dermatol. Ges. 2021, 19, 768-770. [CrossRef]

39. Teoh, Y.L.; Kuan, L.Y.; Chong, W.; Chia, H.Y.; Thng, T.G.; Chuah, S.Y. The role of reflectance confocal microscopy in the diagnosis and management of squamous cell carcinoma in situ treated with photodynamic therapy. Int. J. Dermatol. 2019, 58, 1382-1387. [CrossRef]

40. Hoogedoorn, L.; Peppelman, M.; Van De Kerkhof, P.C.M.; Van Erp, P.E.J.; Gerritsen, M.J.P. The value of in vivo reflectance confocal microscopy in the diagnosis and monitoring of inflammatory and infectious skin diseases: A systematic review. Br. J. Dermatol. 2015, 172, 1222-1248. [CrossRef]

41. Navarrete-Dechent, C.; Cordova, M.; Liopyris, K.; Aleissa, S.; Rajadhyaksha, M.; Cohen, G.; Marghoob, A.A.; Rossi, A.M.; Barker, C.A. In vivo imaging characterization of basal cell carcinoma and cutaneous response to high-dose ionizing radiation therapy: A prospective study of reflectance confocal microscopy, dermoscopy, and ultrasonography. J. Am. Acad. Dermatol. 2021, 84, 1575-1584. [CrossRef]

42. Witkowski, A.; Ludzik, J.; Soyer, H.P. Telediagnosis with Confocal Microscopy: A Reality or a Dream? Dermatol. Clin. 2016, 34, 505-512. [CrossRef]

43. Hicks, S.P.; Swindells, K.J.; Middelkamp-Hup, M.A.; Sifakis, M.A.; González, E.; González, S. Confocal histopathology of irritant contact dermatitis in vivo and the impact of skin color (black vs. white). J. Am. Acad. Dermatol. 2003, 48, 727-734. [CrossRef] [PubMed]

44. Jang, W.H.; Shim, S.; Wang, T.; Yoon, Y.; Jang, W.S.; Myung, J.K.; Park, S.; Kim, K.H. In vivo characterization of early-stage radiation skin injury in a mouse model by two-photon microscopy. Sci. Rep. 2016, 6, 19216. [CrossRef] [PubMed]

45. Lee, J.; Jang, W.H.; Shim, S.; Kim, B.; Myung, J.K.; Park, S.; Kim, K.H. Characterization of early-stage cutaneous radiation injury by using optical coherence tomography angiography. Biomed. Opt. Express 2020, 11, 2652-2664. [CrossRef] [PubMed] 